\title{
O desenvolvimento do conceito Poulantziano de hegemonia
}

Octávio Fonseca Del Passo ${ }^{1}$

Resumo: Esse artigo visa mostrar como se deu o desenvolvimento do conceito de hegemonia de Nicos Poulantzas, utilizando como referência o artigo "Observações Preliminares" e o livro Poder Político $e$ Classes Sociais. Em um segundo momento, abordamos como esse conceito foi desenvolvido e utilizado pela "Escola de Campinas". Por fim, reclamamos pela incorporação das políticas sociais no método para a análise da hegemonia em um bloco no poder.

Palavras-chave: Poulantzas. Classes sociais. Bloco no Poder. Hegemonia. Políticas sociais.

Abstract: This article aims to show how Nicos Poulantzas' concept of hegemony developed in his work, using as a reference the article "Preliminary Observations" and the book Political Power and Social Classes. In a second moment, we approach how the poulantzian concept of hegemony was developed and practically used in the "School of Campinas". Finally, we demand the incorporation of social policies in the method for the analysis of hegemony in a bloc in power. Keywords: Poulantzas. Social classes. Power Block. Hegemony. Social politics.

\footnotetext{
${ }^{1}$ Doutorando em Ciência Política pelo IFCH/UNICAMP. E-mail: octaviodelpasso@ gmail.com
} 


\section{A elaboração inicial do conceito de hegemonia de Poulantzas}

A teoria marxista do Estado foi desenvolvida por Nicos Poulantzas ${ }^{2}$ de maneira rápida e consistente, de modo que causou grande impacto no pensamento e na prática acadêmica e política de vários países ${ }^{3}$. Este artigo expõe de maneira sintética a contribuição feita por Poulantzas para a teoria marxista do Estado ao desenvolver o conceito dehegemonia e, mais especificamente, abordaremos a evolução que o conceito de hegemonia teve internamente ao pensamento deste autor. Para tanto, utilizamos como referência o artigo Gramsci: entre Sartre et Althusser. Préliminaires à l'étude de l'hégemonie dans l'Etat ${ }^{4}$ (1980), elaborado em sua fase ${ }^{5}$ de inspiração sartreana e a obra elaborada em sua fase de inspiração mais próxima do "estruturalismo", Pouvoir Politique et Classes Sociales ${ }^{6}$ (PPCS), lançado na França no emblemático ano de 1968.

2 Poulantzas nasceu em Atenas no ano de 1936 e morreu no ano de 1979 em Paris, onde lecionava desde a década de 1960. Era filósofo de formação e membro do Partido Comunista da Grécia, passando posteriormente às fileiras do Partido Comunista Francês.

${ }^{3}$ Em grande medida a rapidez e a intensidade da difusão das ideias desenvolvidas por Poulantzas pode ser atribuída ao debate que ele provocou com Ralph Milliband. Segundo Bianchi (2007), por ser travado em língua inglesa, esse debate fez com que as ideias de Poulantzas alcançassem um público que ainda desconhecia sua obra recémlançada em francês.

${ }^{4}$ Este artigo será referenciado daqui em diante como "Observações preliminares".

${ }^{5}$ Fazemos uma junção de duas propostas de periodizações das obras de Nicos Poulantzas. Assumimos a periodização feita por Jessop (2009), que coloca como período de transição para o estruturalismo as publicações feitas entre os anos de 1964 - 1968, e a periodização feita por Codato (2008) que separa as obras entre os anos de 1968 e 1969 como produções de análise estruturalista do Estado, as publicações entre os anos 1970 e 1974 como análises funcionalistas do Estado e as que foram produzidas entre os anos de 1976 e 1978, que seriam análises relacionistas do Estado.

${ }^{6}$ No Brasil, esta obra foi lançada pela Editora Martins Fontes no ano de $1977 \mathrm{com}$ o título Poder Político e Classes Sociais. Doravante o livro será referenciado pela sigla PPCS.

$90 \quad$ O desenvolvimento do conceito... 
A elaboração inicial de algumas ideias e conceitos contidos em PPCS foram fruto dos estudos que constituíram a base teórica de Poulantzas e que ocorreram ao longo da transição epistemológica percorrida pelo autor no começo de sua vida acadêmica, passando de uma análise existencial-marxista de inspiração sartreana para uma análise "estruturalista" 7, da região do político nas formações sociais capitalistas, que eram mais inspiradas nas ideias desenvolvidas por Althusser e por Gramsci - embora este último tenha recebido muitas críticas direcionadas ao seu historicismo.

No artigo de transição intitulado "Observações preliminares", Poulantzas já lançava mão das ideias desenvolvidas nas obras de Gramsci para repreender a abordagem, que ele considera ser instrumental, realizada pelo chamado "marxismo ortodoxo". Nessa fase, Poulantzas já apontava que o Estado em geral deve ser tratado como uma estrutura específica que acarreta efeitos próprios sobre o processo de reprodução das sociedades divididas em classes e que estas são constituídas pelo próprio Estado ${ }^{8}$. No entanto, nesse mesmo texto, o autor menciona a separação existente no modo de produção capitalista entre as esferas econômica, política e ideológica, que seria uma importante novidade desse novo modo de produção ao possibilitar, na prática, a existência de uma oposição entre os interesses privados e os interesses políticos. Foi essa separação que permitiu uma nova forma de dominação de classe que não mais se restringe ao monopólio formal do poder político.

As análises de Poulantzas que foram realizadas sobre esse prisma teórico, mostraram que o Estado, no modo de produção capitalista,

7 Utilizamos os termos "estruturalista" e "estruturalismo" entre aspas para destacar a diferença que temos em relação ao conteúdo pejorativo que vem sendo acriticamente associado a eles. Com a utilização desses termos quero simplesmente me referir às análises que priorizaram o entendimento dos mecanismos e dos instrumentos de reprodução dos modos de produção (no caso de Poulantzas, o modo de produção capitalista), as suas causas e as suas consequências em detrimento dos estudos que priorizam os mecanismos de ruptura social.

${ }^{8}$ Jessop, 2009. 
tornou-se compatível com a representação do poder popular e passou a delegar responsabilidade ao povo, que é convocada a participar da política através do sufrágio universal. Em consequência, o Estado capitalista deve garantir a existência de uma representatividade mínima do interesse "universal" dos cidadãos, ao menos de maneira formal, como condição de sua legitimidade. Essa tarefa estatal é objetivada de maneira eficiente graças à possibilidade aberta por esse novo tipo de Estado que realiza uma mediação entre os interesses privados e os interesses políticos gerais ${ }^{9}$ da classe dominante.

Esta condição de mediação prática é, portanto, particular do Estado capitalista e faz com que o embate político pelo seu controle seja orientado através da disputa pelo domínio da posição política que permite universalizar os interesses particulares de determinada classe ou fração de classe social. Contudo, em "Observações Preliminares", Poulantzas ainda não tem uma teoria completamente desenvolvida, já que, nesse artigo, ele ainda recorria a uma operação analítica que tem como pressuposto a separação entre o Estado e a sociedade civil. Pressuposto elaborado por Antonio Gramsci e que, independentemente de Poulantzas o ter abandonado posteriormente, permitiu que ele fizesse sofisticadas críticas aos três tipos de visões ainda comuns às teorias sobre o Estado. A primeira diz respeito à ideia de que o poder estatal é uma expressão direta da consciência de classe da classe politicamente dominante; a segunda é a noção de que a unidade de uma formação social específica é o resultado da imposição política feita por um sujeito da classe hegemônica; e, por fim, a terceira visão é a que defende que as ideias dominantes de uma época são as ideias das classes dominantes ${ }^{10}$.

Conforme adiantado, os pressupostos gramscianos foram posteriormente abandonados por Poulantzas e criticados de maneira contundente em PPCS. A renúncia de Poulantzas aos pressupostos

\footnotetext{
${ }^{9}$ Idem.

${ }^{10}$ Idem.
}

92 O desenvolvimento do conceito... 
gramscianos permitiu com que ele criasse formulações ainda mais precisas e sintéticas que dariam uma resposta mais incisiva às críticas que já haviam sido previamente feitas em "Observações Preliminares". Em PPCS, a formulação do conceito de hegemonia se desenvolve no sentido de rejeitar as três visões sobre o Estado que apresentamos. Tal rejeição é feita porque essas visões têm em comum a negação da autonomia intrínseca à superestrutura política. A elaboração mais refinada dos conceitos poulantzianos que foram apresentados em PPCS dependeu, desse modo, da compreensão de que a superestrutura política no modo de produção capitalista é um nível específico de uma formação social ${ }^{11}$ determinada.

\section{O aprimoramento conceitual}

Os principais avanços teóricos realizados por Poulantzas em PPCS desenvolvem-se em torno do conceito de bloco no poder, que é, em síntese, a unidade contraditória de todas as camadas, classes e frações das classes dominantes ${ }^{12}$ de um determinado modo de produção em uma formação social específica ${ }^{13}$, a fim do compartilhamento do poder político e da manutenção de seus objetivos políticos estratégicos em comum. A reprodução dessa unidade contraditória é garantida através do Estado capitalista e sua autonomia relativa frente às classes e frações de classe dominantes, o que permite que o Estado tenha uma estratégia de desenvolvimento do modo de produção capitalista a despeito das estratégias das classes e frações de classe que compõem o bloco no poder. Essa estratégia desenvolvida pelo Estado, em vista da sua autonomia relativa, pode ser implantada mesmo que a sua

\footnotetext{
${ }^{11}$ POULANTZAS, 1977.

12 Utilizo classes dominantes no plural porque as formações sociais concretas geralmente comportam mais de um modo de produção, de maneira que pode haver, nesses casos, mais de uma classe dominante. É o caso, por exemplo, do Brasil, como mostrou Francisco Pereira de Farias (2017).
}

${ }^{13}$ POULANTZAS, 1977, p. 229. 
aplicação seja, na prática, em detrimento dos objetivos de curto prazo das classes ou frações de classe dominantes. O Estado capitalista é, portanto, uma arena de conflito, mas é também um ator político que formula ativa e estrategicamente o desenvolvimento capitalista.

O conceito de bloco no poder desenvolvido por Poulantzas é importante, pois ele possibilita que o analista político sane muitos erros comuns e intrínsecos ao ofício do cientista social quando exercido no momento em que os fatos ocorrem como foram os casos dos erros opostos e simétricos ${ }^{14}$ cometidos por Marx nas obras $O 18$ de Brumário de Luís Bonaparte (2011) e Guerra Civil na França (2011). Nessas obras, a caracterização do Estado no período dos governos de Luís Bonaparte na França oscila entre um Estado que representa a fusão dos interesses das classes e frações de classe dominantes e um Estado que representa com exclusividade os interesses financeiros. $\mathrm{O}$ conceito de bloco no poder desenvolvido por Poulantzas permite, portanto, um avanço nas análises concretas à medida que capta uma representação prioritária (hegemônica) sem, no entanto, excluir os interesses das demais classes e frações dominantes, porém subordinados à fração hegemônica.

O bloco no poder não é, no entanto, um loteamento do poder político do Estado entre as classes e frações de classe dominantes de determinada formação social. Mas, é a unidade própria do Estado capitalista combinado com a sua autonomia relativa, que se dá na media em que as classes e frações de classe dominantes só têm a possibilidade de garantirem a manutenção da sua dominação enquanto agem politicamente unificadas. Justamente pelo fato de que as classes e frações de classe dominantes não conseguem manter a sua dominação política com a repartição do poder político é que elas precisam do Estado capitalista agindo enquanto instrumento organizador da unidade propriamente política do bloco no poder, que se realiza sob a égide de uma fração hegemônica. Assim, "a unidade do poder de

14 Agradeço aos colegas do CEMARX, com quem pude perceber essa oscilação em Marx e, por isso, o quão refinado é o conceito de bloco no poder.

$94 \quad$ O desenvolvimento do conceito... 
Estado reside, em última análise, na sua relação particular com a classe ou fração hegemônica, no fato da correspondência unívoca do Estado com os interesses específicos dessa classe ou fração" ${ }^{15}$. Ou seja, Poulantzas aponta que há uma correspondência entre os interesses do Estado e os interesses específicos da classe ou fração de classe hegemônica no bloco no poder.

O conceito de hegemonia está, portanto, associado diretamente ao conceito de bloco no poder. Ele existe justamente para designar a classe ou fração de classe que tem, dentro do bloco no poder, a capacidade de representar, necessariamente, duas características possíveis da dominação política de classes ${ }^{16}$ dentro das formações sociais capitalistas: a) capacidade de representar o interesse do povo/ nação e; b) a competência de garantir a sua dominância específica, dentre as próprias classes e frações de classe dominantes, na sua relação com o Estado capitalista. Por consequência, o conceito de hegemonia aparece aplicado às práticas políticas da classe dominante, mas é revestido de dois sentidos, pois indica a constituição dos interesses políticos das classes dominantes e a sua relação com o Estado capitalista como representativo do "interesse geral" da nação e que tem, por sua vez, o efeito de isolamento econômico e o aumento da dificuldade de organização política das classes e frações de classe dominadas. Vejamos, nas palavras do autor, como ele conceitua a palavra hegemonia:

1) Indica a constituição dos interesses políticos dessas classes, na sua relação com o Estado capitalista, como representativos de "interesse geral" desse corpo político que é o "povo-nação" e que tem como substrato o efeito de isolamento econômico.

\footnotetext{
${ }^{15}$ POULANTZAS, 1977, p. 297-298, grifos do próprio autor.

${ }^{16}$ Este fato não exclui, todavia, a possibilidade de haver defasagem entre elas, de modo que nem sempre as duas funções sejam coincidentes na mesma classe ou fração de classe num mesmo período cronológico (POULANTZAS, 1977).
} 
(...) 2) $\mathrm{O}$ conceito de hegemonia reveste igualmente uma outra acepção, a qual não é de fato indicada por Gramsci. Veremos, com efeito, que o Estado capitalista e as características específicas da luta de classes em uma formação capitalista tornam possível o funcionamento de um "bloco no poder", composto de várias classes ou frações politicamente dominantes. Entre essas classes e frações dominantes, uma delas detém um papel dominante particular, o qual pode ser caracterizado como papel hegemônico. Nesse segundo sentido, o conceito de hegemonia exprime a dominação particular de uma das classes ou frações dominantes em relação às outras classes ou frações dominantes de uma formação social capitalista. (POULANTZAS, 1977, p. 137-138)

Em síntese, podemos dizer que apesar de o bloco no poder agregar o conjunto de todas as classes e frações de classe politicamente dominante em uma formação social específica, ele permite que uma classe ou fração de classe dominante faça com que o Estado capitalista manifeste prioritariamente a sua dominação particular, através de mecanismos que fazem com que esse interesse se revista como interesse geral do povo, da nação.

\section{O desenvolvimento da teoria e da prática poulantziana na "Escola de Campinas"}

No processo de desenvolvimento do conceito de hegemonia de Poulantzas que mostramos acima, percebemos que, apesar de este autor ter sido bem sucedido em sua empreitada mais geral (elaboração de uma teoria do Estado capitalista) e de uma mais específica (desenvolver o conceito já existente de hegemonia), ele não obteve o mesmo sucesso ao precisar a metodologia para que o analista que se debruça sobre o processo político de uma formação social específica identifique corretamente a dominação particular de uma classe ou fração de classe dentro do bloco no poder em uma dada conjuntura.

\begin{tabular}{l|l}
\hline 96 & O desenvolvimento do conceito...
\end{tabular} 
Parte dessa lacuna funcional em análises de casos concretos deixada por Poulantzas foi preenchida pelas contribuições realizadas por Décio Saes ${ }^{17}$, que logrou avançar na delimitação metodológica para a aferição da hegemonia entre as classes e frações de classe dominantes. A complementação ao conceito de hegemonia poulantziano de PPCS feita por Saes é a seguinte:

Como os interesses econômicos próprios às diferentes classes dominantes e frações de classe dominante não podem ser igualmente satisfeitos num momento histórico qualquer - pois todas as partes do conflito objetivam incessantemente aumentar a sua quota de repartição da mais-valia total -, não pode haver, nas formações sociais capitalistas, "partilha igualitária do poder". As diferentes classes e frações que exploram o trabalho de outrem exercem conjuntamente o poder político sobre as classes exploradas. Mas, no seio do bloco das classes dominantes - que Poulantzas denomina bloco no poder -, uma classe ou fração prepondera politicamente sobre as demais, na medida em que seus interesses econômicos são satisfeitos em caráter prioritário. Essa preponderância política de uma classe ou fração no seio do bloco no poder é designada por Poulantzas pelo termo hegemonia. (SAES, 2001, p. 50).

Ou seja, ao perceber que o conceito que Poulantzas desenvolvera ao constatar que a fração hegemonia no bloco no poder tem o seu interesse priorizado pelo Estado ${ }^{18}$ não era suficiente, Saes (2001) aprofundou os seus estudos e concluiu que os interesses da classe ou fração hegemônica no bloco no poder que são priorizados pelo Estado são, mais especificamente, os interesses econômicos. Por consequência,

\footnotetext{
${ }^{17}$ SAES, 2001.

${ }^{18}$ POULANTZAS, 1977, p. 297-298.
} 
a maneira que devemos proceder para identificar uma classe ou fração de classe que ocupa a posição hegemônica na hierarquia entre as classes e frações de classe que compõem o bloco no poder é realizar o cruzamento dos programas das classes e frações das classes dominantes que seja feito com intuito de confrontar os interesses econômicos dessas classes e frações de classe com a política econômica praticada pelo Estado. Esse procedimento tem o intuito de identificar qual a classe ou fração de classe teve as suas demandas econômicas atendidas de forma prioritária pelas políticas de Estado.

A possibilidade de realizar esse confronto comparativo entre a política econômica concreta de um Estado com as reivindicações econômicas das classes ou frações de classe dominantes deriva do método deduzido da teoria Poulantziana para aferir a hegemonia no bloco no poder. Essa elaboração é viável porque o fato de o Estado capitalista desenvolver as políticas econômicas estratégicas - são aquelas que pretendem a manutenção da dominação política burguesa a longo prazo - para o conjunto da classe dominante não é contraditório pela possibilidade dele garantir, no presente, as políticas econômicas táticas para a fração hegemônica. Ou seja, apesar de o Estado estar sempre em harmonia com as políticas econômicas que atendem aos interesses do conjunto das classes e frações de classe dominantes, ele pode agir em resposta à determinada conjuntura de modo que cause prejuízo para as classes e frações de classe que são dominantes, mas que não são hegemônicas. Vale ressaltar que a concretização prioritária da política econômica específica da classe ou fração de classe hegemônica no bloco no poder também se dá porque ela, igualmente, é capaz de fazer com que os seus interesses transpareçam ao conjunto da sociedade como os interesses do "povo nação" 19 .

Ao realizar uma análise do caso concreto do Brasil durante os governos de Lula, Armando Boito Jr. concorda com o aprofundamento da teoria poulantziana realizado por Saes, ao sintetizar a maneira

19 Idem.

\begin{tabular}{l|l}
\hline 98 & O desenvolvimento do conceito...
\end{tabular} 
pela qual ele avalia que um analista deve proceder para encontrar a classe ou fração de classe hegemônica no bloco no poder, da seguinte maneira:

Uma análise rigorosa do bloco no poder vigente no capitalismo neoliberal brasileiro exigiria, de um lado, estabelecer com precisão quais são os segmentos econômicos organizados como fração de classe burguesa e, de outro lado, comparar as demandas, estratégicas e secundárias, das diferentes frações burguesas com as medidas de governo que compõe a política econômica de Estado (BOITO, 2018, p. 63).

No entanto, apesar do consenso estabelecido na "Escola de Campinas" em torno do avanço teórico-metodológico desenvolvido por Décio Saes sobre a especificidade da análise da política econômica para aferição da hegemonia em um bloco no poder de um Estado capitalista, é preciso salientar que esse tipo de Estado apresenta-se ao conjunto das classes e frações de classe como instrumento realizador dos "interesses gerais da nação" não somente pelas políticas econômicas aplicadas por ele, mas também pela realização de outras formas de política de Estado ${ }^{20}$.

Nesse sentido, ao realizar uma análise da política externa brasileira nos governos de FHC e Lula, Tatiana Berringer ${ }^{21}$ percebeu que houve significativa alteração nos padrões da política internacional na transição dos governos do PSDB para os governos do PT, em especial a partir da chegada da grande burguesia interna ${ }^{22}$ na posição

\footnotetext{
20 Designo como políticas de Estado o conjunto das políticas econômica, social e externa.

${ }^{21}$ BERRINGER, 2015.

${ }^{22}$ Em síntese, a grande burguesia interna é formada por setores do agronegócio, da indústria da construção civil, da grande burguesia industrial e pelos grandes bancos nacionais (BOITO, 2018).
} 
de fração hegemônica no bloco no poder, que teria ocorrido no primeiro mandato do ex-presidente Lula. Com essa constatação a autora também deu sua contribuição para o aperfeiçoamento teóricometodológico poulantziano da "Escola de Campinas".

Berringer aprofundou a proposta de Décio Saes ao defender que a política externa de um Estado capitalista deve ser igualmente levada em consideração pelo analista que realiza o exercício de aferir a hegemonia de um bloco no poder em uma dada conjuntura. A argumentação da autora se desenvolve no sentido da defesa de que a política externa nada mais é do que a extensão internacional da política econômica praticada pela fração hegemônica no bloco no poder internamente à sua formação social. Ou seja, a política externa é a política econômica da fração hegemônica no bloco no poder aplicada no exterior.

[...] o Estado não representa os interesses do povo-nação, mas sim, o interesse das classes dominantes, ou melhor, do bloco no poder. A política externa não é, portanto, uma política de Estado autônoma às classes sociais e aos governos. Ela é determinada pela fração hegemônica no bloco no poder e é permeada pelas contradições entre as classes e frações de classe (BERRINGER, 2015. Pp. 57).

Essa atuação política de uma classe ou fração de classe no exterior, a fim de efetivar a sua política econômica em outros países, é resultado da posição hegemônica no bloco no poder de determinada formação social, mas pode, ao mesmo tempo, reforçar a sua hegemonia no bloco no poder à medida que essa classe ou fração de classe conquiste posições na política externa que aumentem o seu poder econômico ou reforce o seu poder político, a depender da correlação de forças no âmbito internacional. 


\section{E a política social?}

Acreditamos que a delimitação teórico-metodológica feita por Saes é mais precisa do que a elaborada por Poulantzas, já que a luta entre as classes e frações de classe dominantes em uma formação social capitalista se dá efetivamente em torno das políticas econômicas de Estado. Mas, é preciso notar que a existência de um interesse dominante dentro do bloco no poder não elimina o fato de que o Estado capitalista referente a ele concretize parte dos interesses das classes e frações de classe dominadas. Desse modo, seguindo a linha das retificações feitas por Décio Saes e por Tatiana Berringer, gostaríamos de acrescentar que a questão da política social dos Estados capitalistas ainda está em aberto, na análise da hegemonia em um bloco no poder.

Ao tratar dessa questão, Saes (2001) omite em algumas passagens de seus textos a política social da sua definição de classe ou fração de classe hegemônica. No entanto, percebemos que ele não exclui a questão das políticas sociais da sua analise empírica. Não se trata, portanto, de propor algo novo, mas apenas de reconhecer que o passo de levar em consideração a política social de um Estado capitalista para aferir a hegemonia em um bloco no poder determinado já foi dado. Ao tratar da questão da hegemonia, Saes demonstra ter ciência da importância do tema, já que afirma, em outro momento, que se pode "sustentar que detém a hegemonia no seio do bloco no poder a classe ou fração cujos interesses econômicos são prioritariamente contemplados pela política econômica e social do Estado" ${ }^{23}$. Eu destaquei a palavra social para dar mais nitidez ao fato de que a aferição da hegemonia a partir da análise da política econômica de um Estado capitalista oscila na definição de Saes. Na prática, ele considera que, além da política econômica de Estado, é preciso ponderar sobre a política social.

Ao analisar a conjuntura política durante os governos Lula, podemos perceber que o analista também deve levar em consideração a

${ }^{23}$ SAES, 2001, p. 51. 
representação dos interesses das classes e frações de classe dominadas para uma aferição mais precisa da hegemonia no seio do bloco no poder. Embora as classes e frações de classes dominadas não componham o bloco no poder, defenderemos que, para aferir a hegemonia no bloco no poder, é preciso analisar não apenas a política econômica, como afirma Saes, e a política externa, como afirma Berringer, mas também a política social, pois é justamente esse o tipo de política que é uma novidade importante do tipo de Estado capitalista ${ }^{24}$.

O conjunto da política econômica interna e externa de um dado Estado sempre será favorável às classes e frações de classe dominantes nessa determinada formação social. No entanto, entendemos que é a análise da política social que nos mostra quais são as classes ou frações de classe dominadas que logram maior sucesso a partir dos efeitos pertinentes ${ }^{25}$ que produzem em uma dada conjuntura. Ou seja, são as políticas sociais que nos evidenciam quais são as classes ou frações de classe dominadas que estão sendo prioritariamente atendidas (entre as classes e frações de classe dominadas - excluídas do bloco no poder) em suas demandas, mostrando com mais precisão a hierarquia de forças existente entre classes e frações de classe dominadas e a relação delas com o bloco no poder e, em especial, com a fração hegemônica.

A possibilidade da representação política das classes e frações de classe dominadas foi aberta graças à característica particular do tipo de Estado capitalista, que apresenta uma autonomia relativa entre a instância econômica e a superestrutura política ${ }^{26}$. Nos limites dos interesses estratégicos do bloco no poder, essa autonomia relativa do

\footnotetext{
${ }^{24}$ POULANTZAS, 1977.

25 Efeitos pertinentes são práticas de classe, ou frações de classe, dominante ou dominada, que são capazes de realizar modificações nas estruturas econômicas, políticas e/ou ideológicas de uma formação social. Eles estão vinculados a uma conjuntura específica e permitem identificar classes sociais distintas nesse processo, mesmo que elas não sejam classes autônomas e que não se expressem na cena política em partidos políticos próprios. Para mais detalhes buscar: POULANTZAS, 1977, p. 179.
}

${ }^{26}$ POULANTZAS, 1977.

102 O desenvolvimento do conceito... 
Estado permite que ele realize concessões às demandas das classes ou frações de classe dominadas que alcançam certo nível de organização política e pressão social. Esse papel de realizar concessões táticas para garantir a manutenção dos interesses estratégicos das classes e frações de classes dominantes desempenhado pelo Estado implica que as lutas especificamente políticas das classes e frações de classe dominadas sejam sempre canalizadas para o campo da economia e concretizadas como políticas sociais. Existe, portanto, a possibilidade de que, por imposição de determinada conjuntura política, as políticas sociais sejam concretizadas pelo Estado graças a sua autonomia relativa. Nesse caso, as políticas sociais são concretizadas pelo Estado à revelia da classe ou fração de classe hegemônica - ou mesmo ao conjunto da classe dominante. Nessa situação, as políticas sociais são uma derrota tática imposta pelo Estado às classes dominantes em troca da garantia da manutenção dos interesses estratégicos dessas mesmas classes e frações de classe.

No entanto, acreditamos que há uma segunda possibilidade de concretização das políticas sociais, que ocorre quando a conjuntura permite a formação de alianças entre as classes e frações de classe dominantes, em especial a hegemônica, com as classes e frações de classe dominadas. Nesse caso, a concretização das políticas sociais seria o resultado da conjugação das demandas das classes e frações de classe dominadas com as demandas da classe ou fração de classe hegemônica no bloco no poder. Há, portanto, nessas situações, um ajuste da política econômica que a fração hegemônica no bloco no poder realiza por conta dos compromissos que adquiriu com as classes e frações de classe dominadas em forma de alianças ou apoio.

Apesar de aparentemente endossarem a definição sintética de Saes, que delimita a aferição da hegemonia no bloco no poder à analise da política econômica, muitos analistas políticos da "Escola de Campinas" que utilizam essa chave teórica, na prática, trabalham com a ideia ampliada que inclui, no processo de aferição da hegemonia, a análise da política social. Além do próprio Décio Saes, que, como vimos acima, oscila entre a sua definição anunciada e a sua análise prática, 
podemos citar o caso da análise que Berringer faz da política externa dos governos Lula. A autora diz que em seu conjunto, "as políticas externa, econômicas e social contribuíram para o deslocamento da hegemonia inconteste do grande capital financeiro internacional e da burguesia compradora no seio do bloco no poder" 27 . Francisco Farias $^{28}$ também parece endossar a visão de que devemos levar em consideração as políticas sociais, já que para ele uma fração prevalece sobre as demais frações das classes dominantes dentro do bloco no poder, quando essa predominância "se traduz na capacidade dessa fração de obter prioritariamente os benefícios da política econômica e social do Estado" ${ }^{29}$. Armando Boito Jr. ${ }^{30}$, apesar de frisar em seus textos que a análise da política econômica é o que prevalece, também parece concordar, já que analisando o caso concreto do bloco no poder no período de transição dos governos de FHC para os governos de Lula, ele afirma que "a grande burguesia compradora e a grande burguesia interna podem se revezar na posição central nesse bloco no poder sem promover alterações de fundo na política econômica e social e sem provocar rupturas institucionais no Estado ou no regime político" 31. Em síntese, acreditamos que mesmo que os autores não tenham incorporado na sua definição teórica eles consideram a política social em suas análises dos casos concretos.

Acreditamos que, a despeito da anunciação teórica mais restrita, essa maneira prática de aferir a hegemonia do bloco no poder que os autores que citamos realizam está correta. A ideia de nação e de representatividade do interesse geral de um determinado conjunto nacional não é uma simples ideia mistificadora ${ }^{32}$ e nem a de representatividade das classes e frações de classe dominadas. Elas têm

\footnotetext{
${ }^{27}$ BERRINGER, 2015, p. 150.

${ }^{28}$ FARIAS, 2017.

${ }^{29}$ Idem, p. 35 . O destaque em itálico é meu.

${ }^{30}$ BOITO JR., 2018.

${ }^{31}$ Idem, p. 64. O destaque em itálico é meu.

32 POULANTZAS, 1977.
}

104 O desenvolvimento do conceito... 
um lastro material real e concreto que varia de acordo com a correlação de forças entre as classes e frações de classe social. As implicações concretas da autonomia relativa de Estado e das políticas sociais são significativas e existe um instrumento conceitual na teoria do Estado de Poulantzas chamado equilíbrio instável de compromisso, que compreende exatamente uma situação em que existe uma fração hegemônica dentro de um bloco no poder que faz concessões necessárias às classes dominadas para que haja, por parte do Estado, absorção da pressão política que elas realizam. A autonomia relativa do Estado é a garantia de que os interesses políticos estratégicos das classes dominantes não serão colocados em risco pelas demandas das classes e frações de classe dominadas. O conceito é denominado de equilíbrio instável de compromissos, na medida em que cada uma dessas palavras significa:

1) Compromisso: na medida em que esse poder corresponde a uma dominação hegemônica de classes, pode dar conta de interesses econômicos de certas classes dominadas, eventualmente contrários ao interesse econômico a curto prazo das classes dominantes, sem que isso atinja o plano dos interesses políticos;

2) Equilíbrio: na medida em que esses "sacrifícios" econômicos, embora reais e criando assim o campo de um equilíbrio, não põem, enquanto tais, em questão o poder político, que fixa precisamente os limites desse equilíbrio;

3) Instável: na medida em que esses limites do equilíbrio são fixados pela conjuntura política. (POULANTZAS, 1977, p. 187)

Esse equilíbrio "de modo nenhum indica, segundo a imagem da balança, qualquer equivalência de poder entre as forças presentes" ${ }^{33} \mathrm{e}$ a ausência desse equilíbrio entre as classes e frações de classes sociais

${ }^{33}$ POULANTZAS, 1977, p. 187. 
podem assumir diferentes características, dependendo da conjuntura ${ }^{34}$. Através desse equilíbrio instável de compromisso, o Estado capitalista adequa os interesses das classes e frações de classe dominadas aos limites políticos impostos pela composição do bloco no poder, para que, assim, ele possa conciliá-los com os interesses econômicos hegemônicos.

Podemos dizer, portanto, que o Estado capitalista transforma as demandas políticas e econômicas das classes e frações de classe dominadas em políticas sociais, as quais se concretizam por meio de diferentes formas devido ao fato de que elas dependem da classe ou fração de classe que se encontra hegemônica no bloco no poder. Sendo assim, a maior ou menor absorção das demandas que são exteriores ao bloco no poder, ou seja, das classes dominadas, mas que o Estado concretiza e, sobretudo, a qualidade como elas são absorvidas não mudam apenas de acordo com a conjuntura política e econômica, mas também de acordo com a classe ou fração de classe que está ocupando a posição hegemônica no seio do bloco no poder nessa conjuntura específica. Se nossa hipótese estiver correta, ela abre a possibilidade de indicarmos que uma alteração das políticas sociais também pode ocorrer devido à necessidade de readequá-las a uma nova hegemonia no bloco no poder, se nesse caso a nova força hegemônica tem um programa econômico minimamente diferente do programa anterior. Mas não apenas isso, já que a confirmação dessa hipótese também abre a possibilidade de apontarmos que a política social pode sofrer mudanças de acordo com as variações das alianças e das classes-apoio ${ }^{35}$

\footnotetext{
${ }^{34}$ Algumas possíveis variações são entre o capital interno e o capital externo de uma formação social; entre o capital bancário e o capital produtivo. Ainda há o fracionamento transversal aos dois descritos, balizado entre pequeno, médio e grande capital. Ou seja, pode prevalecer o fracionamento de acordo com a regionalidade do capital, de acordo com o setor de acumulação do capital ou de acordo com o tamanho (FARIAS, 2009).

${ }^{35}$ As classes ou frações-apoios distinguem-se das classes ou frações do bloco no poder e das classes ou frações aliadas a ele. Em primeiro lugar, a diferenciação se dá devido às contradições entre ambas e um segundo motivo deve-se ao fato de que a sustentação
} 
que gravitam em torno da classe ou fração de classe hegemônica no bloco no poder.

Para exemplificar nossa hipótese, podemos utilizar o caso concreto do Brasil baseado na tese elaborada por Armando Boito Jr. ${ }^{36}$, que enquadra esses governos como o resultado de um processo que culminou em uma frente política denominada frente neodesenvolvimentista ${ }^{37}$. Com o exemplo da tese dos governos neodesenvolvimentistas de Lula e Dilma, podemos notar como as políticas sociais foram fundamentais para o entendimento da importância política dos trabalhadores organizados dentro da frente neodesenvolvimentista. Embora esses governos não tenham rompido com o modelo macroeconômico neoliberal dos anos 90, implantado pela hegemonia da grande burguesia associada ao capital externo, a política econômica foi alterada em favor da grande burguesia interna, no entanto essa alteração foi feita de modo a favorecer as classes e frações de classe dominadas que desempenharam as funções de classes aliadas e classes-apoio dessa nova fração hegemônica. Os trabalhadores organizados e aos trabalhadores da massa marginal passaram a ser priorizados pelas políticas sociais de Estado e não mais exclusivamente a classe média, como acontecia na década de 90, quando a burguesia associada era hegemônica (BOITO JR., 1999) e, atualmente, como ocorre no governo de Michel Temer.

que as classes ou frações-apoios dão ao bloco no poder "não é em geral baseado em qualquer sacrifício político real dos interesses do bloco no poder e das classes aliadas em seu favor" (POULANTZAS, 1977, p. 238).

${ }^{36}$ Em síntese, a tese de Boito Jr. defende que o neodesenvolvimentismo é o desenvolvimentismo dentro dos limites do capitalismo neoliberal periférico. É resultado do processo que aconteceu nos governos Lula, quando houve uma melhora gradativa da grande burguesia interna no bloco no poder que culminou com sua chegada à posição hegemônica (BOITO JR., 2018).

${ }^{37} \mathrm{~A}$ frente neodesenvolvimentista tem a grande burguesia interna como força dirigente, os trabalhadores organizados como força social principal e os trabalhadores da massa marginal são classe-apoio (BOITO JR. 2018). 
Um exemplo sintomático de que houve nesse governo uma troca de hegemonia política no bloco no poder com a consequente alteração da classe aliada é o programa Minha Casa Minha Vida, que foi criado em 2009 pelo ex-presidente Lula e chegou ao seu pico no ano de 2013, quando o governo se comprometeu a financiar 913 mil unidades habitacionais, enquanto que, no primeiro ano de governo Temer, o compromisso do governo foi de 610 mil unidades e cumpriu apenas $72,5 \%$ da meta, construindo 442,2 mil unidades. No entanto, um olhar mais detalhado para essa política social revela que a base de sustentação do governo mudou dos trabalhadores da massa marginal para a classe média quando se constata que, das 442,2 mil unidades construídas por Temer em 2017, apenas 23 mil (13,5\%) foram destinadas a famílias que pertencem a faixa 1 do programa, ou seja, que ganham até 1,8 mil. A grande maioria foi destinada às faixas 2 e 3 , que atendem as famílias que ganham até 9 mil (GADELHA \& ALVES, 2018). O coordenador do MTST sintetizou ironicamente essa mudança dizendo que essa política não deve ser mais considerada como um programa social, mas como um programa de financiamento imobiliário. Por outro lado, o ministro das Cidades, o deputado Alexandre Baldy, afirmou que "o não cumprimento da meta é um fato. Mas, pretendemos criar um modelo de seleção de projetos que vise deixar dinâmico e célere o processo de contratação do faixa 1" (GADELHA \& ALVES, 2018). Ou seja, a queda do número de unidades habitacionais financiadas para os trabalhadores da massa marginal caiu simplesmente porque esse setor não é mais prioritário para o governo, já que ele não mais é sustentado por essa força social.

\section{Considerações finais}

As mudanças nos três tipos de políticas (econômica, externa e social) de Estado que aconteceram nos governos do PT não foram suficientes para que extrapolassem os limites do modelo neoliberal, mas elas são notáveis, em especial as alterações que aconteceram

108 O desenvolvimento do conceito... 
com as políticas sociais. Essas modificações são resultado da melhor qualidade com que os efeitos pertinentes da grande burguesia interna, dos trabalhadores organizados e de ampla parcela dos trabalhadores da massa marginal agindo em convergência foram produzidos a partir da confluência conjuntural entre as demandas dessas frações de classe, que ocorreu em decorrência dos resultados negativos que a política neoliberal aplicada pela grande burguesia associada na década de 90 teve para elas.

Ao lograr a hegemonia do bloco no poder durante os governos de Lula, a grande burguesia interna fez com que a posição que os trabalhadores da massa marginal e os trabalhadores organizados ocupavam nas políticas de Estado também melhorasse em decorrência da participação que essas frações de classe têm na frente neodesenvolvimentista. Essa nova situação fazia com que a grande burguesia interna garantisse com que suas políticas econômicas fossem conjugadas prioritariamente com as demandas das frações de classe dominadas, que garantiam a sua sustentação na posição dominante ${ }^{38}$ no bloco no poder. Desse modo, as demais classes e frações de classe dominadas eram beneficiadas de maneira secundária, mas o fato nos serve como evidência de que há uma nova posição hegemônica da grande burguesia interna no bloco no poder.

Sendo assim, faz sentido falarmos em uma hegemonia da grande burguesia interna no bloco no poder nos governos Lula, utilizando como parâmetro o cruzamento do seu programa econômico com as políticas sociais efetivadas pelo Estado para as suas classes e frações de classe aliada e apoio. Do mesmo modo, podemos afirmar que a análise das políticas sociais nos ajuda a afirmar com mais segurança

\footnotetext{
${ }^{38}$ As frações de classe dominadas que compunham a frente neodesenvolvimentista não eram a força dirigente, mas a principal força social. Tanto em termos de mobilização social (trabalhadores organizados urbanos e rurais) quanto em termos de votos, já que nesse período houve um realinhamento eleitoral e os votos que garantiram a permanência dos governos petistas foram principalmente os votos dos trabalhadores desorganizados que Singer denomina de trabalhadores subproletários (SINGER, 2015) e nós estamos chamando de trabalhadores da massa marginal.
} 
a existência de uma frente neodesenvolvimentista e a compreender o seu caráter, em decorrência da possibilidade de aferirmos a hegemonia no bloco no poder através das políticas de Estado, inclusas, portanto, às políticas sociais.

\section{Referências bibliográficas}

BIANCHI, Alvaro. Trazendo o Estado de volta para a teoria: o debate Poulantzas-Miliband revisitado. ANPOCS, 2007. Disponível em: $<$ http://www.anpocs.com/index.php/papers-31-encontro/st-7/ st22-4/2997-alvarobianchi-trazendo/file>. Acesso realizado em: 30 de março de 2018.

BOITO JR., Armando. Reforma e Crise Política no Brasil. Os conflitos de Classe nos Governos do PT. Campinas, SP: Editora Unicamp / São Paulo, SP: Editora Unesp, 2018.

BOITO JR., Armando. Política Neoliberal e Sindicalismo no Brasil. Editora Xama, São Paulo, 1999.

BERRINGER, Tatiana. A burguesia brasileira e a política externa nos governos FHC e Lula. Curitiba, Editora Appris, 2015.

CODATO, Adriano. "Poulantzas, o Estado e a Revolução". In: Crítica Marxista, n. 27, 2008, p. 65-85.

FARIAS, Francisco Pereira de. "Frações burguesas e bloco no poder: uma reflexão a partir dos trabalhos de Nicos Poulantzas". In: Crítica Marxista, v. 28, 2009.

FARIAS, Francisco Pereira de. Estado Burguês e Classes dominantes no Brasil (1930-1964). Curitiba, Editora CRV, 2017.

$110 \quad$ O desenvolvimento do conceito... 
GADELHA, Igor. ALVES, Murilo Rodrigues. Governo cumpre só $13,5 \%$ da meta do Minha Casa Minha Vida para os mais pobres. O Estado de S. Paulo, São Paulo, 14 de Janeiro de 2018. Disponível em: <https://economia.estadao.com.br/noticias/ geral,governo-cumpre-so-13-5-da-meta-do-minha-casa-paramais-pobres,70002149698>. Acesso em: 15 de Outubro de 2018.

JESSOP, Bob. "Althusser, Poulantzas, Buci-Glucksmann: desenvolvimentos ulteriores do conceito gramsciano de Estado integral". In: Crítica Marxista, n. 29, 2009, p. 97-121.

MARX, Karl. O 18 de Brumário de Luís Bonaparte. São Paulo, Editora Boitempo, 2011.

MARX, Karl. A Guerra Civil na França. São Paulo, Editora Boitempo, 2011.

POULANTZAS, Nicos. Poder Políticos e Classes Sociais. Martins Fontes. São Paulo, 1977.

POULANTZAS, Nicos. "Gramsci: entre Sartre et Althusser. Préliminaires à l'étude de l'hégemonie dans l'Etat". In: Repères. François Maspero, 1980. p. 33-108.

SAES, Décio A. M. de. "Estado e classes sociais no capitalismo brasileiro dos anos 70-80". In: República do Capital, São Paulo, Boitempo Editorial, 2001, p. 49-70.

SINGER, André. O lulismo em crise: Um quebra cabeças do período Dilma Rousseff (2011-2016). Companhia das Letras, São Paulo, 2018. 
